\title{
The Characters of Chinese Culture behind the Relationship between Mother-in-Law and Daughter-in-Law in China
}

\author{
Du Yichao \\ School of Foreign Language, Nanjing Normal University, Nanjing 210023, China
}

\begin{abstract}
The Article focus on the relationship between mother-in-law and daughter-in-law in China, analyzing the cultural reasons behind it. It's affected by two main factors - the tradition Filial Piety and the conflict between traditional views and the new culture.
\end{abstract}

Keywords: Chinese culture, Filial piety, Family relationship.

\section{Introduction}

In the film Pushing Hands directed by Ang Lee, there are irreconcilable contradictions between the Chinese father and the American daughter-in-law due to huge cultural differences. The film shows the confrontation between two cultures from different countries. But actually in China, without such differences between Chinese and American cultures, the relationship between mother-in-law and daughter-in-law is a frequent topic of discussion, often accompanied by some phrases like "mama's boy". There are always so many conflicts between mother-in-law and daughter-in-law. In few countries are the conflicts as general as in China. That is related to the Chinese traditional culture.

Filial piety is very important in Chinese culture. "Of the hundred excellent things, filial piety is the first". Although it originated from the traditional ancestor worship and has religious nature, with the long historical development, under the transformation of Confucian culture, it has become one of the most important moral qualities of the Chinese people [1]. In modern society, filial piety still exerts a powerful constraint on the Chinese people. However, with the development of industrialization and modernization, the values of young people are also changing. When the demand of filial piety which puts parents first conflicts with the individual needs of the child, contradictions inevitably arise. The contradiction between young couples and the man's parents is very common. It's possible that this contradiction is between two child and two parent, and it is also possible between the daughter-in-law and her father-in-law or the daughter-in-law and her mother-in-law. In the film, we just see the relationship between father-in-law and daughter-in-law. But why are we more filed is the conflicts between mother-in-law and daughter-in-law, rather than the conflicts between father-in-law and daughter-in-law. Why do we tend to call some man "mama's boy" rather than "papa's boy"?

\section{The Internal Reason}

\subsection{The Worship of Mother}

Although the traditional Confucian society is a patriarchal society - men occupy the dominant position, and women are in the position of oppression, we found one exception, which is that women are not in the bottom position all the time. When they become mothers, they are to be respected, at least by their sons, because that is what filial piety requires. In traditional Chinese culture, there is no shortage of praise for mothers, such as the stories of Mencius' mother and Yue Fei's mother.

\subsection{The Absence of Male in the Family Relationship}

In addition to the Confucian restraint of filial piety on the son, the way in which the mother and father function in the traditional Chinese family is also important. In the context of "Men working outside and women working inside", women perform their duties at home. She had an influence on her son almost every day in his childhood. Although men are the power and legal authority in Confucian society, they do not necessarily play a more prominent role in family life than women. Influenced by the co-construction of family and state, men should care more about the country, politics and their big family, and they pay little attention to themselves and their wives and children. A lot of times they're not involved in the child's development - except when the child needs to be punished for mistakes. Even in modern society, most father figures are fixed in people's minds in this way. On the other hand, mothers don't give up the responsibility. The continuation of Confucian spirit cannot be separated from mothers. "The primary emotional tie in Confucian societies was between mother and son, not husband and wife" [2]. From these, we can also see that women can play a special role in the patriarchal society.

\subsection{The Construction of the Relationship}

Under such cultural background, the relationship between the mother and the child is thus constructed. In terms of the mother's attitude towards her son, it is easy for a mother to have a strong desire for control over her son. First of all, in a traditional society marked by male, many women cannot feel a sense of security from themselves or their husbands. In the face of her husband, she is often an overlooked character. She can only place her personal fate and hope in her child (and this child should be a son). "A mother becomes noble because of her son", "the mother follows her son when the father dies" such sentences all embody this; Moreover, because of the demands of filial piety, she was able to be respected by her son. In front of her son, she changed from the person who was 
oppressed to a leader of a certain status. Sons also tend to be dependent on their mothers. Because of the discipline "strict father and kind mother", father is often a disciplinarian and an absentee. Meanwhile, mother has influenced the son for a long time and played an indelible role in his life. Nowadays, some Chinese men rely on their mothers when facing important decisions or they can't leave their mother in many aspects of their daily lives. Even if they have a wife, it is hard to get rid of mothers' influence, thus making the wife feel uncomfortable and threatened.

The worship of mother under the background of Chinese culture of filial piety and the absence of male in the relationship between husband and wife and the relationship between father and son in Confucian society have formed a special mother-child relationship. This may be the internal reason why the contradiction between Chinese mother-in-law and daughter-in-law is so prominent.

\section{The Stimulus}

As I mentioned earlier, the values of young people have changed. Modern Chinese culture also incorporates many features of the new culture. We can see the change of women' $\mathrm{s}$ status and the development of the idea of equality. Just as the conflict between Chinese culture and American culture in the film Pushing Hands, the conflict between traditional Chinese culture and modern Chinese culture is also obvious. The contradiction between mother-in-law and daughter-in-law is a concrete embodiment of this conflict. The development of times, the renewal of culture, these factors have an effect on the relationship between mother-in-law and daughter-in-law from outside.

\subsection{The Unity and Collectivization}

For example, the family concept in traditional Chinese culture emphasizes the unity and collectivization of a family. "Bring up sons to support parents in their old age." Even if the son becomes an independent person and has his own family and career, he still needs to bring his parents to him and serve them so that they can enjoy family harmony. This is also why many older people ask to live with their children. But modern young people have a strong sense of freedom, considering their own time and personal space, they often do not want to live with their parents. In fact, nowadays in China, it is quite common for children to live apart from their parents due to population mobility. But there are still many parents stay with their married sons. When parents and married sons live together, more conflict occurs. The traditional role of women in family life has not changed much - Women are still the main role in the house and the bearers of housework. In this case, the son and father-in-law can easily become the roles outside the door. Conflicts between mothers-in-law and daughters-in-law, the two hostesses are more likely to erupt.

\subsection{The Conflict of the Idea of Procreation}

The conflict of the idea of procreation is also an important factor. In traditional Chinese culture, "The more sons, the more blessings", so parents often want to have grandchildren of their own. However, modern women are often unwilling to reflect their value by giving birth to children. And giving birth to children will bring some disadvantages to them. May it will cause damage to their body or work. Therefore, some women choose to deliver a baby later or not at all, which causes great conflicts between the two sides. The role of mothers-in-law in this conflict is more complicated. As a woman, she should have been the understanding of the other women. Maybe she was similarly oppressed. However, under the influence of the spirit of traditional culture, she has become a staunch supporter and defender of the family line. "After many years, the daughter-in-law finally becomes the mother-in-law", she begins to put the pressure on the next daughter-in-law. And maybe she may think is not a kind of pressure, but a habit or normality.

\section{Equations}

In summary, behind the relationship between mother-in-law and daughter-in-law lie profound cultural reasons, which are rooted in traditional Chinese culture and emerge with the conflict between traditional culture and modern culture. It may be difficult to solve the problem completely, because the deep cultural forces behind it are hard to shake. The culture of filial piety has something worth passing on, but sometimes it can also cause distress and cause serious family problems. As is finally reflected in the pushing hands, the conflict between the two different forms of culture ultimately needs to be understood and compromised to reach a relatively stable and balanced state. This approach is also more in line with the characteristics of Chinese culture. It also gives us some inspiration to deal with the relationship between mother-in-law and daughter-in-law.

\section{References}

[1] BA Xinsheng, SONG Na, "A Study on the Evolution of Filial Piety during the Pre-Qin Period," Journal of Tianjin Normal University (Social Science) (2), pp. 17-26, 2016.

[2] WH. Slote, "Oedipal Ties and the Issue of Separation-Individuation in Traditional Confucian Societies," The Journal of the American Academy of Psychoanalysis, XX (3), pp.435-53, 1992. 